\title{
Nonlinear Observers for Predicting State-of-Charge and State-of-Health of Lead-Acid Batteries for Hybrid-Electric Vehicles
}

\author{
B. S. Bhangu, Member, IEEE, P. Bentley, D. A. Stone, and C. M. Bingham, Member, IEEE
}

\begin{abstract}
This paper describes the application of state-estimation techniques for the real-time prediction of the state-of-charge (SoC) and state-of-health (SoH) of lead-acid cells. Specifically, approaches based on the well-known Kalman Filter (KF) and Extended Kalman Filter (EKF), are presented, using a generic cell model, to provide correction for offset, drift, and long-term state divergence-an unfortunate feature of more traditional coulomb-counting techniques. The underlying dynamic behavior of each cell is modeled using two capacitors (bulk and surface) and three resistors (terminal, surface, and end), from which the SoC is determined from the voltage present on the bulk capacitor. Although the structure of the model has been previously reported for describing the characteristics of lithium-ion cells, here it is shown to also provide an alternative to commonly employed models of lead-acid cells when used in conjunction with a KF to estimate SoC and an EKF to predict state-of-health $(\mathrm{SoH})$. Measurements using real-time road data are used to compare the performance of conventional integration-based methods for estimating SoC with those predicted from the presented state estimation schemes. Results show that the proposed methodologies are superior to more traditional techniques, with accuracy in determining the SoC within $2 \%$ being demonstrated. Moreover, by accounting for the nonlinearities present within the dynamic cell model, the application of an EKF is shown to provide verifiable indications of SoH of the cell pack.
\end{abstract}

Index Terms-Batteries, Kalman Filter, observers, state-ofcharge, state-of-health.

\section{INTRODUCTION}

$\mathbf{P}$ EAK power buffers of hybrid-electric vehicles (HEVs) are, by their very nature, subject to large dynamic transients in current and power demand. An example is the RHOLAB driving cycle requirements, introduced in Section V-C, which shows road data collected from a Honda Insight HEV, where peak charge- and discharge-current demands of $\approx 60 \mathrm{~A}$ and $\approx$ $-100 \mathrm{~A}$, respectively, are required from the battery pack when subjected to a series of vehicle driving tests [1]. The accommodation of such operating conditions requires that the man-

Manuscript received October 1, 2004; revised November 19, 2004. This work was supported by the United Kingdom's Department of Trade and Industry (DTI) Foresight Vehicle Link Program and by the United Kingdom's Engineering and Physical Sciences Research Council (EPSRC), who funded the Reliable Highly Optimized Lead Acid Battery (RHOLAB) project jointly with the European Advanced Lead Acid Battery Consortium, and Hawker Batteries, as well as by the other partners in the project, namely, Provector, Ltd., the University of Warwick, and Hawker Batteries (now part of Enersys Inc.). The review of this paper was coordinated by Prof. A. Emadi.

The authors are with the Department of Electronic and Electrical Engineering, University of Sheffield, Sheffield S1 3JD, U.K. (e-mail: b.bhangu@sheffield.ac.uk).

Digital Object Identifier 10.1109/TVT.2004.842461 agement system have accurate knowledge of the peak power buffer's state of charge (SoC) to facilitate safe and efficient operation. Failure to control SoC, leading to under- or over-charging conditions, can degrade the ability of the pack to source/sink subsequent power transients.

Various electric equivalent circuit models have been applied to lead-acid batteries to determine SoC. However, the complex nonlinear electrochemical processes that occur during power transfer to/from the battery has, in the past, proven difficult to accurately describe dynamically. These processes include the flow of ions, amount of stored charge, ability to deliver instantaneous power, and the effects of temperature and internal pressure, to name a few. An accurate determination of SoC is required, in particular, for the efficient utilization of the battery for HEVs to optimize performance, extend the lifetime, and prevent progressive permanent damage to the battery. Although, in theory, the SoC of a battery can be determined from terminal quantities in conjunction with an appropriate battery model, inaccuracies and measurement noise ultimately introduce errors that can become significant over time. Increased accuracy in the estimation of SoC, therefore, facilitates safe and efficient operation of the battery under HEV driving duties.

A variety of techniques have been proposed to measure or monitor the SoC of a cell or battery, each having its relative merits, as reviewed by Piller et al. [2]. Charge counting or current integration is, at present, the most commonly used technique, requiring dynamic measurement of the cell/battery current, the time integral of which is considered to provide a direct indication of SoC [3]. However, due to the reliance on integration, errors in terminal measurements due to noise, resolution, and rounding are cumulative and large SoC errors can result. A reset or recalibration action is, therefore, required at regular intervals-in all electric vehicles (EVs). This may be carried out during a full charge or conditioning discharge, but is less appropriate for standard HEV operation where full SoC is rarely achieved. Other factors that ultimately influence the accuracy of SoC estimates, and create additional complications for the traditional integration-based techniques, are the variation of cell capacity with discharge rate, temperature, and Coulombic efficiency losses.

When considering flooded lead-acid cells, the specific gravity of the electrolyte is known to be a good measure of SoC. However, estimates of SoC are complicated when using valve regulated lead-acid (VRLA) cells due to the nominal amount of electrolyte being immobilized in the glass fiber separator mat or gel. Nevertheless, since the open-circuit terminal voltage of a VRLA 


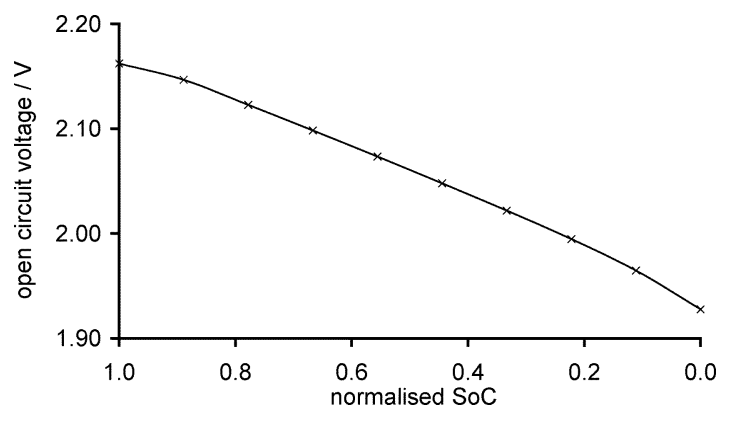

Fig. 1. Open circuit voltage versus SoC.

battery varies almost linearly over the majority of the battery's SoC [4] (see Fig. 1), it has been used in many SoC estimators. For the method to be effective, however, corrections must be made for temperature and electrolyte concentration gradients (concentration polarization) formed during high-rate charge and discharges (long settling times may be required to allow such concentration gradients to disperse prior to making an open circuit voltage reading [4]). More commonly, therefore, the measured open-circuit voltage is used to periodically correct the estimated SoC derived from other charge integration techniques. However, as with measurements of specific gravity, suitable periods of operational inactivity may not occur frequently enough in HEV driving duties for this to be successfully utilized.

Cell-impedance measurements have also been reported as a useful technique for resetting or adjusting SoC estimates from integration-based methods. However, from results of various studies undertaken to identify the impedance variation of cells/batteries, with SoC [5], [6], contradictory views to their usefulness in practical systems currently remain unresolved [2].

Other reported methods for estimating SoC have been based on artificial neural networks [7] and fuzzy logic [8] principles, although the latter was reported to have relative poor performance. Although such techniques incur large computation overhead on the battery pack controller, which would in the past have led to problems for online implementation, the increasing computational power of digital signal processing chips and the accompanying fall in device costs may, in the near future, make their application an attractive alternative. Neural networks, in particular, have been used to avoid the need for the large number of empirically derived parameters required by other methods. Indeed, for application to the less demanding task of prediction of $\mathrm{SoC}$ in portable equipment, a neural network modeling approach has been shown to give mean errors of $\approx 3 \%$ [9]. Also, a neural network model for predicting battery power capacity during driving cycles has been added to the ADVISOR EV and HEV modeling environments [10].

Ultimately, manufacturers of HEVs would like predictions of the state-of-health $(\mathrm{SoH})$ or state-of-function $(\mathrm{SoF})$ of a battery pack, since the increasing reliance on drive-by-wire technologies is making the battery a key safety-critical component of the vehicle. Knowledge of whether a battery will fail when subjected to high transient loadings, as may be experienced in emergency braking, for instance, is therefore essential. However, SoH monitoring techniques are currently in their infancy, with little being reported to date.

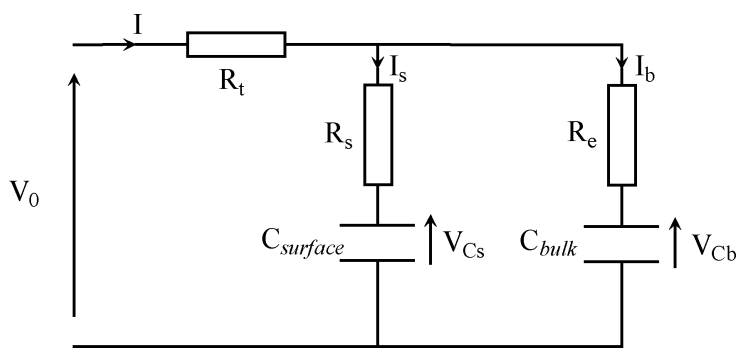

Fig. 2. $R C$ battery model schematic.

Here then, model-based state-estimation techniques are proposed for predicting the states of a cell that would normally be difficult or expensive to measure, or are subject to the significant problems described previously - the SoC being the key state in this case. Using an error-correction mechanism, the observers provide real-time predictions of SoC. Specifically, the well-known Kalman filter (KF), developed during the 1960s to provide a recursive solution to optimal linear filtering, for both state observation and prediction problems [11], [12], is used for this study; a unique feature of the KF is that it optimally (minimum variance) estimates states affected by broadband noise contained within the system bandwidth, i.e., that cannot otherwise be filtered out using classical techniques, and enables empirical tradeoffs between modeling errors and the influence of noise.

Furthermore, the model is extended to accommodate $\mathrm{SoH}$ via the real-time estimation of bulk capacitance. Due to the resulting nonlinearities of the underlying dynamic model, an EKF is considered for real-time estimation to monitor bulk capacitance while cycling a cell. Experimental results ultimately show the ability of the EKF to compensate for inaccuracies in the initial estimates of cell model bulk capacitance and to track changes in the value of the bulk capacitance that can be considered as a measure of the cell's capacity.

\section{BATTERY MODEL}

A dynamic model of the battery, in the form of state variable equations, is necessary to predict the SoC or SoH. Here, a generic model [13] consisting of a bulk capacitor $C_{\text {bulk }}$ to characterize the ability of the battery to store charge, a capacitor to model surface capacitance and diffusion effects within the cell $C_{\text {surface }}$, a terminal resistance $R_{t}$, surface resistance $R_{s}$ and end resistance $R_{e}$, is used-see Fig. 2. The voltage across the bulk and surface capacitors are denoted $V_{C b}$ and $V_{C s}$, respectively.

Initial parameters of the cell are precalculated from experimental data, where open-circuit voltage (OCV) tests are performed upon successive discharges of the battery, by the application of current pulses. An initial estimate of $C_{\text {bulk }}$ is obtained by analyzing the amount of stored energy in the cell, while a provisional value of $C_{\text {surface }}$ relies on calculating the time constant of the cell in response to high-frequency excitation. Complete derivation details, along with the initial parameters for the cells considered, are given in Appendix A, for completeness. 


\section{State VARIABle Description of Battery Model}

A. State Variables $V_{C b}, V_{C s}$, and $V_{0}$

Voltages and currents describing the characteristics of the network shown in Fig. 2, are given by (note: by convention, current flowing into the cell is considered positive)

$$
\begin{gathered}
V_{0}=I R_{t}+I_{b} R_{e}+V_{C b} \\
V_{0}=I R_{t}+I_{s} R_{s}+V_{C s} .
\end{gathered}
$$

Equating the two voltage equations and, after some algebraic manipulation, yields

$$
I_{b} R_{e}=I_{s} R_{s}+V_{C s}-V_{C b}
$$

From Kirchoff's laws, $I=I_{b}+I_{s}$ and from (3)

$$
I_{b}\left(R_{e}+R_{s}\right)=I R_{s}+V_{C s}-V_{C b},
$$

Since $I_{b}=\dot{V}_{C b} C_{\text {bulk }}$ (assuming a relatively slow varying $C_{\text {bulk }}$ ), (4) can be rearranged to give

$\dot{V}_{C b}=-\frac{V_{C b}}{C_{\mathrm{bulk}}\left(R_{e}+R_{s}\right)}+\frac{V_{C s}}{C_{\mathrm{bulk}}\left(R_{e}+R_{s}\right)}+\frac{I R_{s}}{C_{\mathrm{bulk}}\left(R_{e}+R_{s}\right) .}$

Through a similar derivation, the rate of change of the surface capacitor voltage is obtained from (1) and (2) as

$$
\begin{aligned}
\dot{V}_{C s}=-\frac{V_{C s}}{C_{\text {surface }}\left(R_{e}+R_{s}\right)}+\frac{V_{C b}}{C_{\text {surface }}\left(R_{e}+R_{s}\right)} \\
+\frac{I R_{e}}{C_{\text {surface }}\left(R_{e}+R_{s}\right)} .
\end{aligned}
$$

A state variable description relating the voltages and currents is therefore

$$
\begin{aligned}
& {\left[\begin{array}{c}
\dot{V}_{C b} \\
\dot{V}_{C s}
\end{array}\right]=\left[\begin{array}{cc}
-\frac{1}{C_{\text {bulk }}\left(R_{e}+R_{s}\right)} & \frac{1}{C_{\text {bulk }}\left(R_{e}+R_{s}\right)} \\
\frac{1}{C_{\text {surface }}\left(R_{e}+R_{s}\right)} & -\frac{1}{C_{\text {surface }}\left(R_{e}+R_{s}\right)}
\end{array}\right]\left[\begin{array}{c}
V_{C b} \\
\\
V_{C s}
\end{array}\right]} \\
& +\left[\frac{\frac{R_{s}}{C_{\text {bulk }}\left(R_{e}+R_{s}\right)}}{\frac{R_{e}}{C_{\text {surface }}\left(R_{e}+R_{s}\right)}}\right] I
\end{aligned}
$$

and the output voltage, as a function of terminal current, is given from (1) and (2) by

$$
V_{0}=\left[\begin{array}{cc}
\frac{R_{s}}{R_{e}+R_{s}} & \frac{R_{e}}{R_{e}+R_{s}}
\end{array}\right]\left[\begin{array}{c}
V_{C b} \\
V_{C s}
\end{array}\right]+\left[R_{t}+\frac{R_{e} R_{s}}{R_{e}+R_{s}}\right] I .
$$

Taking the time derivative of the output voltage and assuming $d I / d t \approx 0$ (the rate of change of terminal current, per sampling interval when implemented digitally, is negligible) gives

$$
\begin{aligned}
\dot{V}_{0}= & {\left[-\frac{R_{s}}{C_{\text {bulk }}\left(R_{e}+R_{s}\right)^{2}}+\frac{R_{e}}{C_{\text {surface }}\left(R_{e}+R_{s}\right)^{2}}\right] V_{C b} } \\
& +\left[\frac{R_{s}}{C_{\text {bulk }}\left(R_{e}+R_{s}\right)^{2}}-\frac{R_{e}}{C_{\text {surface }}\left(R_{e}+R_{s}\right)^{2}}\right] V_{C s} \\
& +\left[\frac{R_{s}^{2}}{C_{\text {bulk }}\left(R_{e}+R_{s}\right)^{2}}+\frac{R_{e}^{2}}{C_{\text {surface }}\left(R_{e}+R_{s}\right)^{2}}\right] I .
\end{aligned}
$$

Solving for $V_{C s}$ from (8) and substituting into (9) provides the complete state variable description of the network as

$$
\begin{aligned}
& {\left[\begin{array}{c}
\dot{V}_{C b} \\
\dot{V}_{C s} \\
\dot{V}_{0}
\end{array}\right]=\left[\begin{array}{ccc}
-\frac{1}{C_{\text {bulk }}\left(R_{e}+R_{s}\right)} & \frac{1}{C_{\text {bulk }}\left(R_{e}+R_{s}\right)} & 0 \\
\frac{1}{C_{\text {surface }}\left(R_{e}+R_{s}\right)} & -\frac{1}{C_{\text {surface }}\left(R_{e}+R_{s}\right)} & 0 \\
A(3,1) & 0 & A(3,3)
\end{array}\right]} \\
& \times\left[\begin{array}{c}
V_{C b} \\
V_{C s} \\
V_{0}
\end{array}\right] \\
& +\left[\begin{array}{c}
\frac{R_{s}}{C_{\text {bulk }}\left(R_{e}+R_{s}\right)} \\
\frac{R_{e}}{C_{\text {surface }}\left(R_{e}+R_{s}\right)} \\
\frac{R_{e}^{2}}{C_{\text {surface }}\left(R_{e}+R_{s}\right)^{2}}-\frac{R_{s} R_{t}}{C_{\text {bulk }} R_{e}\left(R_{e}+R_{s}\right)} \\
+\frac{R_{t}}{C_{\text {surface }}\left(R_{e}+R_{s}\right)}+\frac{R_{e} R_{s}}{C_{\text {surface }}\left(R_{e}+R_{s}\right)^{2}}
\end{array}\right] I \\
& A(3,1)=-\frac{R_{s}}{C_{\text {bulk }}\left(R_{e}+R_{s}\right)^{2}}+\frac{R_{e}}{C_{\text {surface }}\left(R_{e}+R_{s}\right)^{2}} \\
& -\frac{R_{s}^{2}}{C_{\text {bulk }} R_{e}\left(R_{e}+R_{s}\right)^{2}}+\frac{R_{s}}{C_{\text {surface }}\left(R_{e}+R_{s}\right)^{2}} \\
& A(3,3)=\frac{R_{s}}{C_{\mathrm{bulk}} R_{e}\left(R_{e}+R_{s}\right)}-\frac{1}{C_{\text {surface }}\left(R_{e}+R_{s}\right)} .
\end{aligned}
$$

\section{B. Observability of the RC Battery Model}

Observability of the linear system is investigated from construction of the observability matrix $O_{b}$

$$
O_{b}=\left[\begin{array}{lll}
\mathbf{C} & \mathbf{C A} & \mathbf{C A}^{2}
\end{array}\right]^{T}
$$

where $\mathbf{C}=\left[\begin{array}{lll}0 & 0 & 1\end{array}\right]$ and $\mathbf{A}$ is given by the first term on the righthand side (RHS) of (10). When expanded, $O_{b}$ is [see (12) at the bottom of the page]. Under mild conditions, the observability matrix is always of full rank.

$$
O_{b}=\left[\begin{array}{ccc}
0 & 0 & 1 \\
A(3,1) & 0 & A(3,3) \\
\left(\frac{-A(3,1)}{C_{\text {bulk }}\left(R_{e}+R_{s}\right)}+A(3,1) \cdot A(3,3)\right) & \left(\frac{A(3,1)}{C_{\text {bulk }}\left(R_{e}+R_{s}\right)}\right) & A(3,3)^{2}
\end{array}\right]
$$




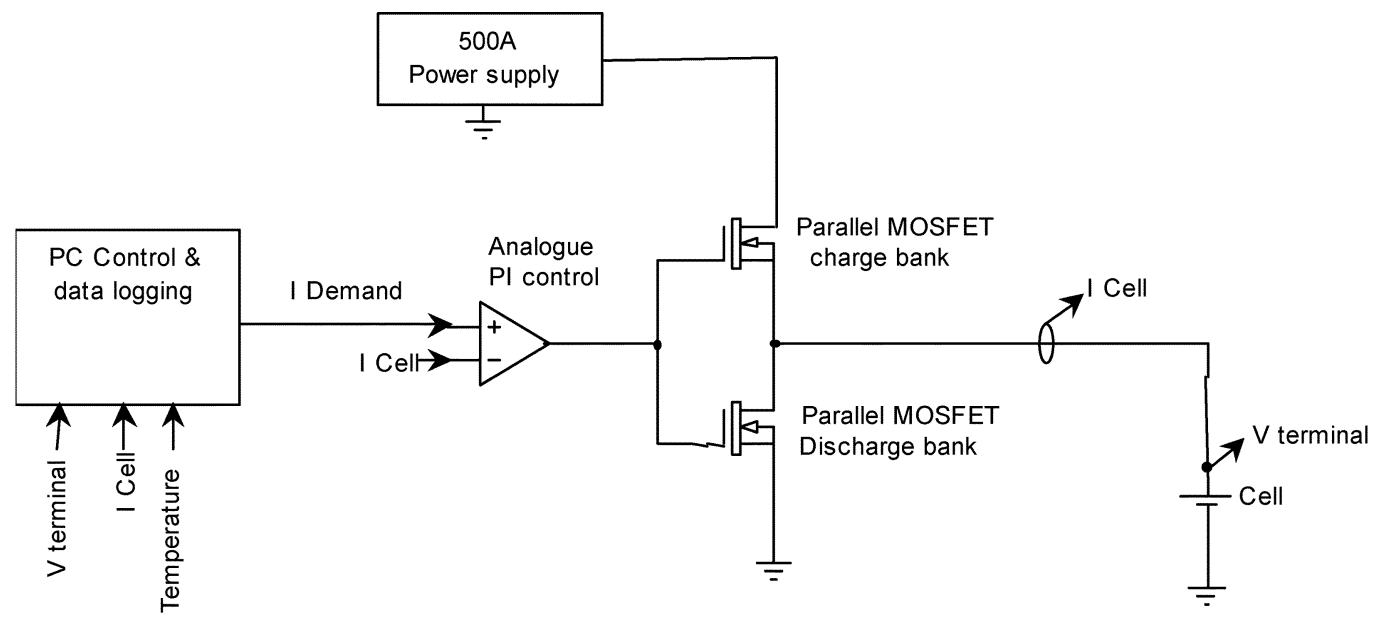

Fig. 3. High-power cell test bench schematic.

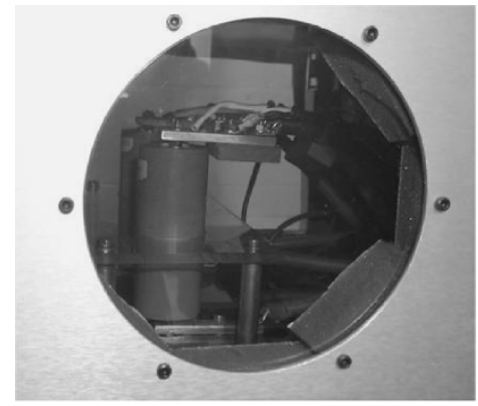

(a)

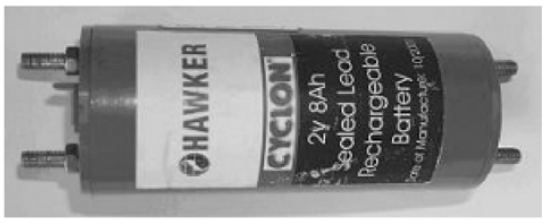

(b)

Fig. 4. (a) Test chamber. (b) 8 Ah sealed lead-acid cell.

\section{VERIFICATION OF THE BATTERY MODEL}

\section{A. High-Power Cell Test Bench}

A high-power cell test bench has been constructed to allow continuous cycling of individual cells using custom power and current profiles, thereby permitting the characterization of individual cells over closely managed operating duties. The cells are contained within a thermally controlled environmental chamber to provide known environmental conditions. A schematic of one channel of the test bench is shown in Fig. 3.

Power for cell charging is supplied from a rectified $3 \phi, 500 \mathrm{~A}$ power supply via a smoothing capacitor bank. The charge/discharge circuits employ an analog PI controller driving two parallel arrays of MOSFET power devices, acting as variable resistors. One array of MOSFETs controls the charging current to the cell, while the other, the discharge current, where both are forced air cooled. The demand signal is provided via a PC-based LabVIEW, National Instrumentation Corporation, Austin, TX, hardware-development platform, the current cycle for the cell being defined within a text file, with cell current, temperature, and voltage being continuously logged at $1 \mathrm{kHz}$. The test facility measures the cell current with Hall-effect current transducers that are auto calibrated at the start of each test. Control signals are generated at $100 \mathrm{~Hz}$ and the analog circuitry has a bandwidth of $6 \mathrm{kHz}$. A photograph of the test facility is given in Fig. 4(a).
Furthermore, a dSPACE system is employed in parallel with the LabVIEW hardware. Measurements of the cell voltages and currents are fed into 16-bit ADCs, from which the observer algorithms estimate SoC (and, ultimately, $\mathrm{SoH}$ ).

The cell tested in this paper is a novel, spiral-wound, $8 \mathrm{Ah}$ sealed lead-acid cell, with terminals on either end, developed by Hawker (ENERSYS, Inc., Reading, PA), for the RHOLAB project [Fig. 4(b)]. The double terminal encapsulation is introduced to lower grid currents and, hence, thermal gradients, and thereby promotes efficient utilization of the active materials in the cell, thus leading to a battery that is optimized for the high-power duties typical of hybrid driving cycles.

\section{B. Evaluation of the RC Model}

The validity of the proposed model is tested prior to the design of the KF. A discharge pulse of $1.53 \mathrm{~A}$ is applied to both the cell and model and a comparison of the output voltage and bulkand surface-capacitor voltages is made. The results are given in Fig. 5. Although some discrepancy exists between the measured and modeled voltages, the underlying dynamic characteristics are essentially the same, with the principle difference being the voltage response between discharge pulses. The offset and drift are due to errors in initial condition estimates and the effect of employing the model in an open-loop state over a long time period. 

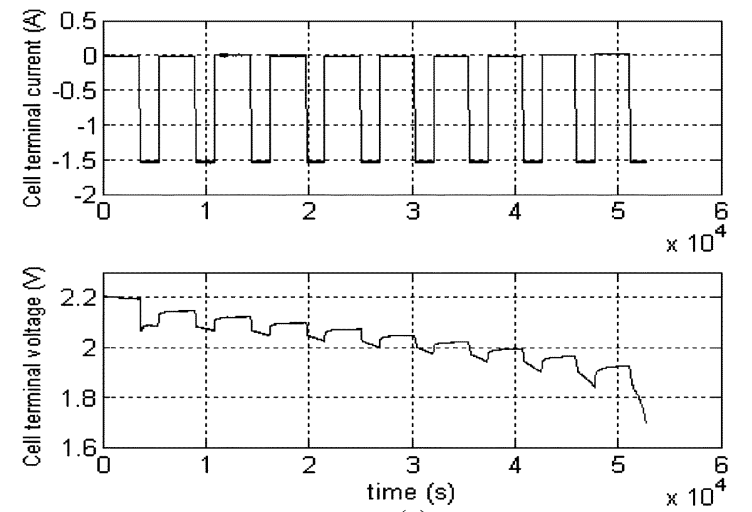

(a)

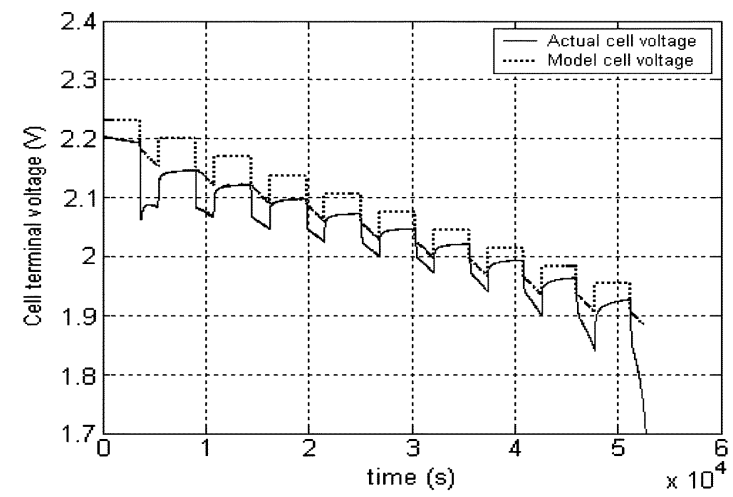

(b)
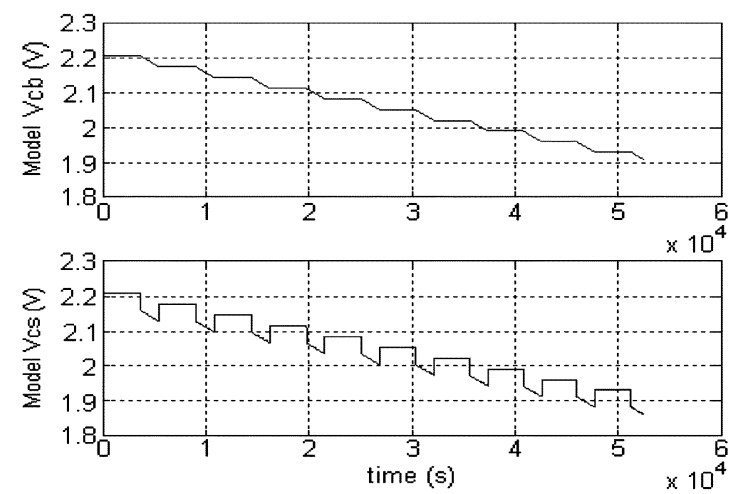

(c)

Fig. 5. Dynamic behavior of RC battery model in response to discharge pulses of 1.53 A. (a) Current and voltage of cell. (b) Measured and modeled cell voltage. (c) Modeled voltages across bulk and surface capacitors.

\section{Formulation OF KF FOR SoC ESTIMATION}

A continuous time-invariant linear system can be described in state-variable form by

$$
\begin{aligned}
& \dot{x}(t)=\mathbf{A} x(t)+\mathbf{B} u(t) \\
& y(t)=\mathbf{C} x(t)
\end{aligned}
$$

where

$u \quad$ vector of applied inputs;

$x \quad$ state vector;

$y \quad$ vector of measured outputs;

A dynamics matrix (time invariant);

B input matrix (time invariant);

C is the measurement matrix (time invariant).

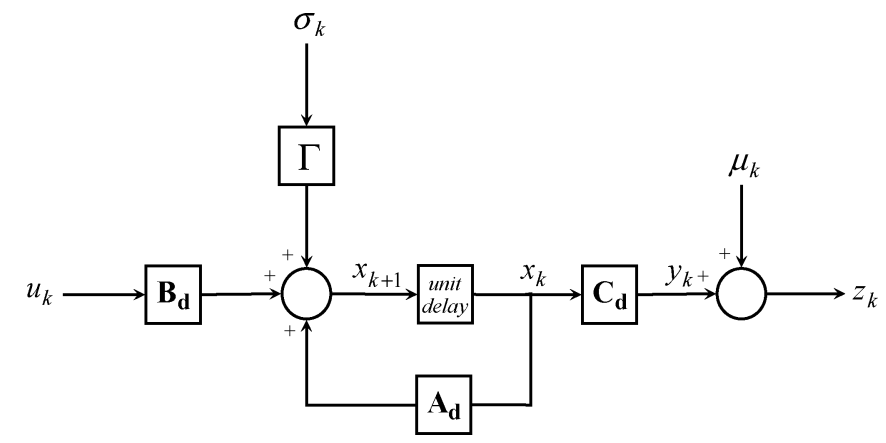

Fig. 6. Discrete system model subject to random disturbances $\sigma_{k}$ and $\mu_{k}$.

Assuming the applied input $u$ is constant during each sampling interval, a discrete-time equivalent model of the system is given by

$$
\begin{aligned}
x_{k+1} & =\mathbf{A}_{\mathbf{d}} x_{k}+\mathbf{B}_{\mathbf{d}} u_{k} \\
y_{k+1} & =\mathbf{C}_{\mathbf{d}} x_{k+1}
\end{aligned}
$$

where

$$
\mathbf{A}_{\mathbf{d}} \approx \mathbf{I}+\mathbf{A T}_{\mathrm{c}} \quad \mathbf{B}_{\mathbf{d}}=\mathbf{B T}_{\mathrm{c}} \quad \mathbf{C}_{\mathbf{d}}=\mathbf{C}
$$

and $\mathrm{T}_{\mathrm{c}}$ is the sampling period. The system is now assumed to be corrupted by stationary Gaussian white noise, via the additive vectors $\sigma_{k}$ and $\mu_{k}$ - the former being used to represent system disturbances and model inaccuracies and the latter representing the effects of measurement noise. Both $\sigma_{k}$ and $\mu_{k}$ are considered to have a zero mean value, for all $k$, with the following covariance matrices ( $E$ denoting the expectation operator):

$$
\begin{array}{ll}
E\left[\sigma_{k} \sigma_{k}^{T}\right]=\mathbf{Q} & \text { for all } k \\
E\left[\mu_{k} \mu_{k}^{T}\right]=\mathbf{R} & \text { for all } k .
\end{array}
$$

The resulting system is, therefore, described by

$$
\begin{aligned}
x_{k+1} & =\mathbf{A}_{\mathbf{d}} x_{k}+\mathbf{B}_{\mathbf{d}} u_{k}+\boldsymbol{\Gamma} \sigma_{k} \\
z_{k+1} & =\mathbf{C}_{\mathbf{d}} x_{k+1}+\mu_{k+1}
\end{aligned}
$$

where

$z \quad$ vector of measured outputs after being corrupted by noise;

$\Gamma \quad$ coupling matrix that governs the influence of the disturbance/modeling inputs on each state

and is shown diagrammatically in Fig. 6.

For notational purposes, $\hat{x}_{(i / j)}$ represents an estimate of $x$ at step $i$ based on all the information up to, and including, time step $j$. A property of the KF is that the estimated state vector $\hat{x}_{(k+1 / k+1)}$ of the system, at time $k+1$, minimizes the sum-ofsquared errors between the actual and estimated states

$$
\min \left\{E\left[\left(x_{k+1}-\hat{x}_{k+1 / k+1}\right)\left(x_{k+1}-\hat{x}_{k+1 / k+1}\right)^{T}\right]\right\} .
$$

For recursive implementation, the KF estimate $\hat{x}_{k+1 / k+1}$ is calculated from the previous state estimate $\hat{x}_{k / k}$, the input $u$, and the measurement signals $z$. The available input/output data at each sample step is, therefore, considered to be 


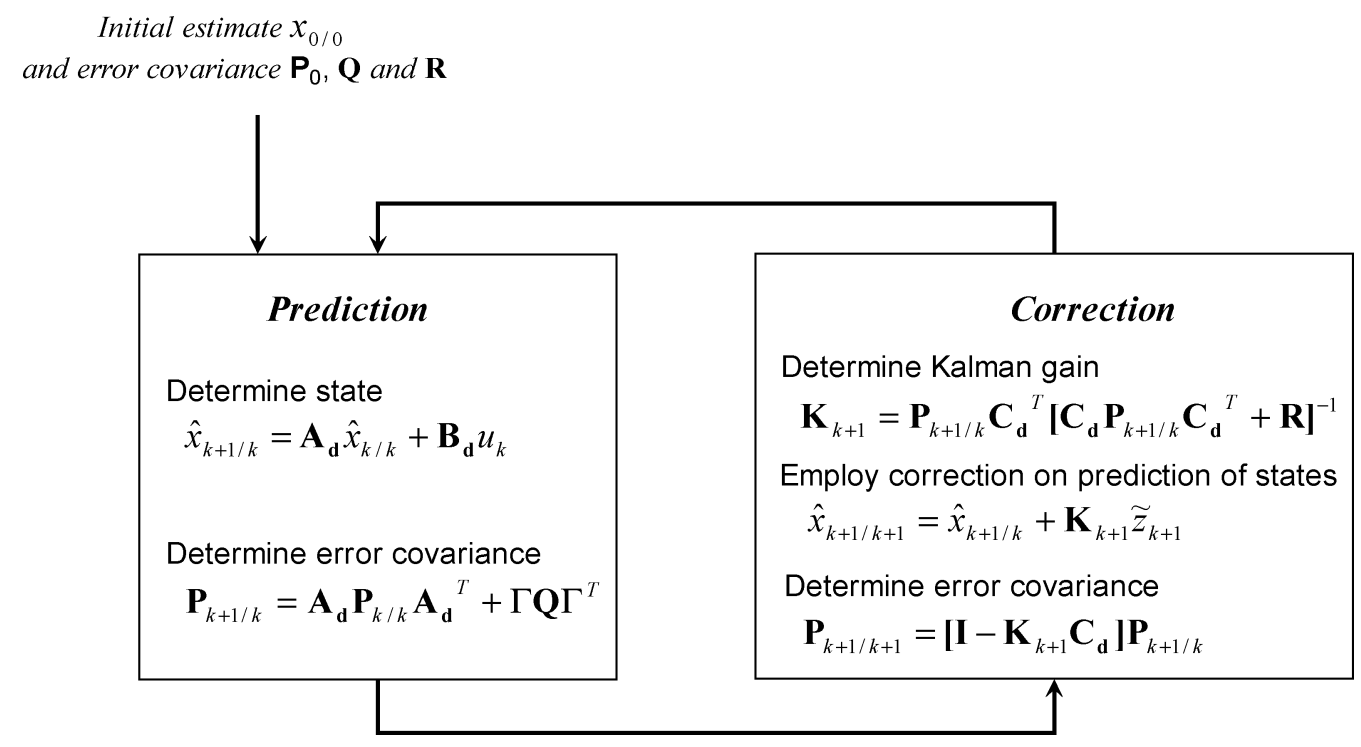

Fig. 7. Recursive KF algorithm.

$u_{0}, u_{1}, u_{2} \ldots u_{k}, u_{k+1}$ and $z_{0}, z_{1}, z_{2} \ldots z_{k}, z_{k+1}$. The recursive $\mathrm{KF}$ algorithm is obtained with the predictor/corrector stages being explicitly identified in Fig. 7.

\section{A. Online Implementation of the KF}

The stochastic principles underpinning the KF are appealing for this investigation, since it is recognized that the presence of disturbances stemming from sensor noise on the cell terminal measurements, and the use of non-ideal dynamic models, make it impossible to predict with certainty the states of the system over prolonged time periods - a statistical predictor/corrector formulation thereby providing obvious advantages.

Since only terminal quantities of the battery can be measured, the input is defined as $u=I$ and the measured output is $y=$ $V_{0}$. Assuming, for now, that cell parameters are time-invariant quantities, the recursive KF algorithm (Fig. 7) is applied, where

$$
\begin{aligned}
& \mathbf{A}_{\mathbf{d}}=\left[\begin{array}{ccc}
1-\frac{T_{c}}{C_{\mathrm{bulk}}\left(R_{e}+R_{s}\right)} & \frac{T_{c}}{C_{\mathrm{bulk}}\left(R_{e}+R_{s}\right)} & 0 \\
\frac{T_{c}}{C_{\text {surface }}\left(R_{e}+R_{s}\right)} & 1-\frac{T_{c}}{C_{\text {surface }}\left(R_{e}+R_{s}\right)} & 0 \\
A_{d}(3,1) & 0 & A_{d}(3,3)
\end{array}\right] \\
& \mathbf{B}_{\mathbf{d}}=\left[\begin{array}{c}
\frac{T_{c} R_{s}}{C_{\mathrm{bulk}}\left(R_{e}+R_{s}\right)} \\
\frac{T_{c} R_{e}}{C_{\text {surface }}\left(R_{e}+R_{s}\right)} \\
\frac{T_{c} R_{e}^{2}}{C_{\text {surface }}\left(R_{e}+R_{s}\right)^{2}}-\frac{T_{c} R_{s} R_{t}}{C_{\text {bulk }} R_{e}\left(R_{e}+R_{s}\right)} \\
+\frac{T_{c} R_{t}}{C_{\text {surface }}\left(R_{e}+R_{s}\right)}+\frac{T_{c} R_{e} R_{s}}{C_{\text {surface }}\left(R_{e}+R_{s}\right)^{2}}
\end{array}\right] \\
& \mathbf{C}_{\mathbf{d}}=\mathbf{C}
\end{aligned}
$$

where

$$
\begin{aligned}
A_{d}(3,1)= & -\frac{T_{c} R_{s}}{C_{\mathrm{bulk}}\left(R_{e}+R_{s}\right)^{2}}+\frac{T_{c} R_{e}}{C_{\text {surface }}\left(R_{e}+R_{s}\right)^{2}} \\
& -\frac{T_{c} R_{s}^{2}}{C_{\mathrm{bulk}} R_{e}\left(R_{e}+R_{s}\right)^{2}}+\frac{T_{c} R_{s}}{C_{\text {surface }}\left(R_{e}+R_{s}\right)^{2}} \\
A_{d}(3,3)= & 1+\frac{T_{c} R_{s}}{C_{\mathrm{bulk}} R_{e}\left(R_{e}+R_{s}\right)}-\frac{T_{c}}{C_{\text {surface }}\left(R_{e}+R_{s}\right)} .
\end{aligned}
$$

Although no formal stability and tuning methods are available for initializing the $\mathrm{KF}$, and recourse to empirical tuning is normally required, its use is nevertheless widespread. Information about the system noise contribution is contained in matrices $\mathbf{Q}$ and $\mathbf{R}$ and, in essence, the selection of $\mathbf{Q}$ and $\mathbf{R}$ determine the accuracy of the filter's performance, since they mutually determine the action of the KF gain matrix $\mathbf{K}_{k+1}$ and estimation error covariance matrix $\mathbf{P}_{k+1 / k+1}$. The covariance matrix representing measurement noise $\mathbf{R}$ can be estimated from knowledge of the battery terminal voltage. The variance is obtained from the square of the root-mean-square (rms) noise on each cell, and is assumed to be Gaussian distributed and independent.

Initialization of the covariance matrix describing disturbances on the plant $\mathbf{Q}$ is complicated by the fact that knowledge of model inaccuracies and system disturbances is limited, particularly as each cell has different characteristics. A judicious choice of $\mathbf{Q}$ is, therefore, obtained from experimental studies under the simplifying assumption that there is no correlation between the elements of $\sigma_{k}$ and the noise present on each cell's voltage transducer, thereby leading to a diagonal $\mathbf{Q}$. The initial covariance matrix $\mathbf{P}_{0}$, together with $\mathbf{Q}$ and $\mathbf{R}$, are ultimately therefore chosen to be

$\mathbf{P}_{0}=\left[\begin{array}{lll}1 & 0 & 0 \\ 0 & 1 & 0 \\ 0 & 0 & 1\end{array}\right] \quad \mathbf{Q}=\left[\begin{array}{ccc}0.0008 & 0 & 0 \\ 0 & 0.008 & 0 \\ 0 & 0 & 0.88\end{array}\right] \quad \mathbf{R}=10$

\section{B. Application of the $K F$}

A discharge pulse of $1.53 \mathrm{~A}$, as described in Section IV-B, is applied to both the experimental test battery and to the real-time $\mathrm{KF}$, with feedback of terminal current as its input. A comparison of the actual and estimated output voltage, and the voltages across the bulk and surface capacitors, are shown in Fig. 8, where excellent convergence can be seen, particularly of output voltage in Fig. 8(a), where the error is negligible except during transients.

It is notable that, for linear systems, after several iterations, $\mathbf{K}_{k+1}$ converges to a constant matrix and, in such cases, $\mathbf{K}_{k+1}$ 

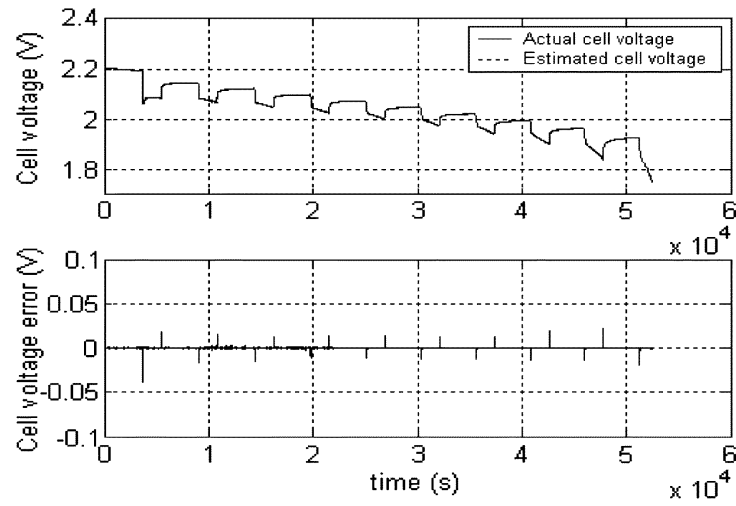

(a)
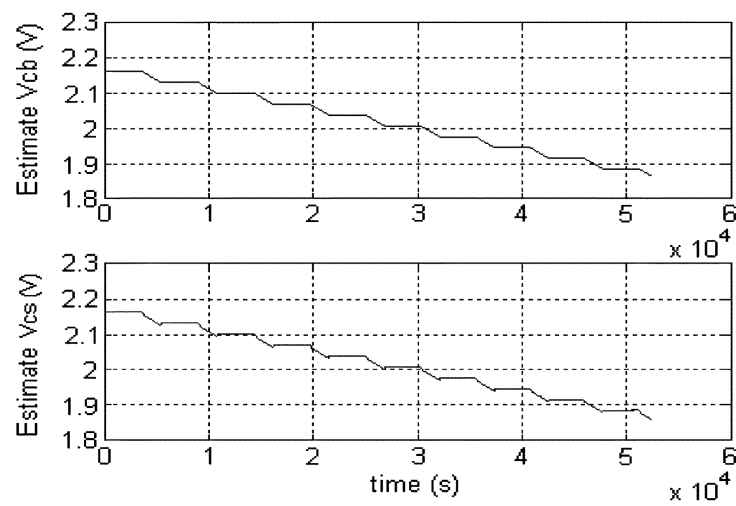

(b)

Fig. 8. Dynamic behavior of KF estimator to discharge pulses of $1.53 \mathrm{~A}$. (a) Actual and estimated cell voltage and voltage error. (b) Estimated bulk and surface capacitor voltages.

can be precalculated offline, thereby presenting significant savings in computational load at the expense of potentially incurring a loss of accuracy during transients. Experimental studies reveal that $\mathbf{K}_{k+1}$ converges to a constant value within $4 \mathrm{~s}$ to

$$
\mathbf{K}_{k+1}=\left[\begin{array}{c}
1.158 \times 10^{-4} \\
-3.134 \times 10^{-4} \\
2.559 \times 10^{-1}
\end{array}\right] .
$$

Fig. 9 shows the difference between using a static and dynamic Kalman correction gain matrix. The results demonstrate that a significant computational saving, typically by a factor of $\approx 1.5$, can be obtained by employing the static gain with a negligible loss of state convergence accuracy.

The impact of the covariance matrix $\mathbf{R}$ on the estimation performance of the KF is shown in Fig. 10, where it is seen that although significant noise is present on the cell terminal voltage measurements, careful selection of $\mathbf{R}$ can provide estimates with enhanced noise immunity.

\section{Comparison of SoC Estimation Techniques}

The KF is applied to the real-time estimation of SoC of a single cell that is subject to a RHOLAB driving cycle [1] (see Fig. 11). The initial cell $\mathrm{SoC}$ is set to 0.8 , this being the defined operating point for partial $\mathrm{SoC}$ on the HEV driving profile. Note that $\mathrm{SoC}=1$ is a normalized value used to define a fully charged cell. Fig. 12 shows the SoC estimated by charge integration and

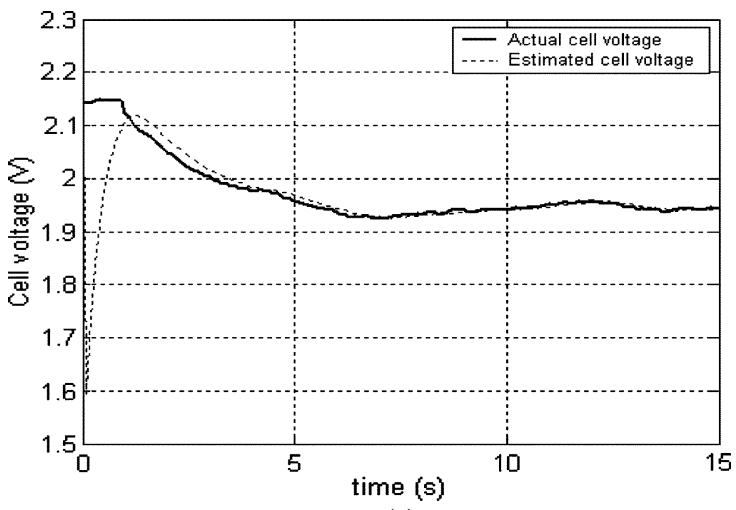

(a)

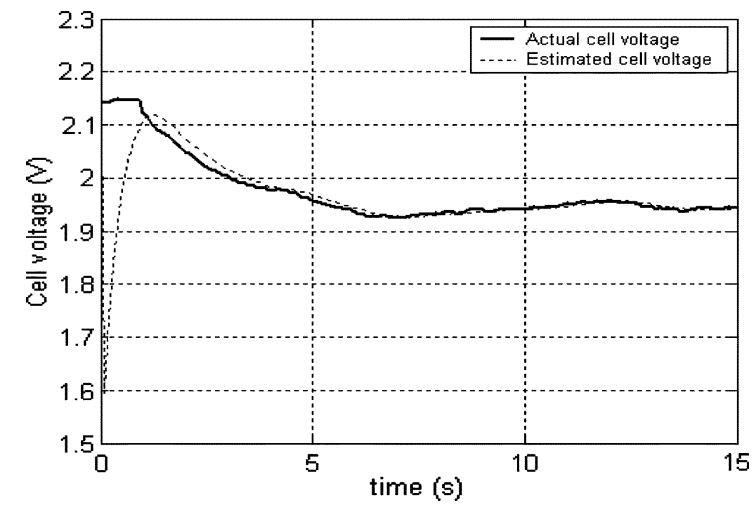

(b)

Fig. 9. Convergence of output voltage using Kalman correction gain. (a) Static gain. (b) Dynamic gain.
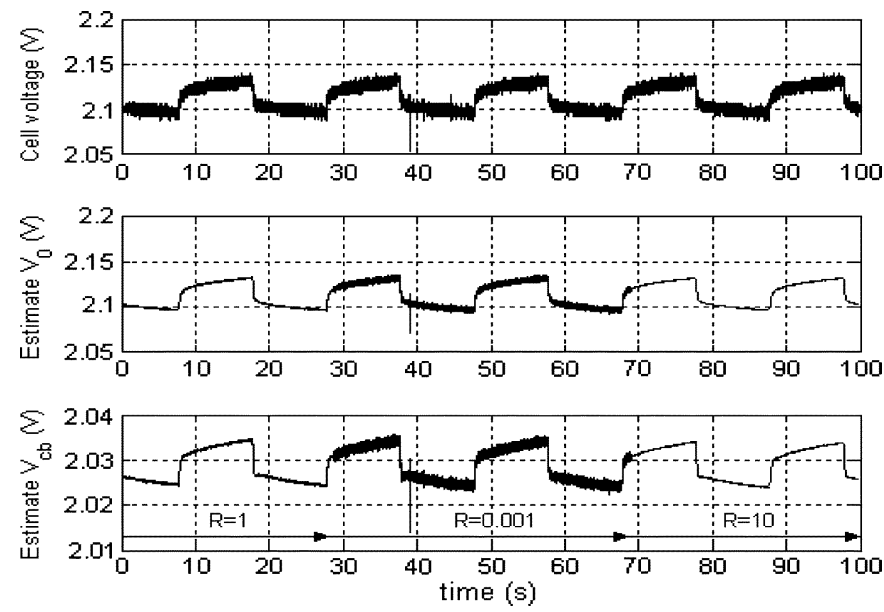

Fig. 10. Impact of the covariance matrix $(\mathbf{R}=1, \mathbf{R}=0.001, \mathbf{R}=10)$ on the states of the KF.

the KF, upon initially discharging the cell from a SoC of 1 to 0.8 . The RHOLAB driving cell-current profile, Fig. 11, is subsequently applied to the cell. Results using conventional SoC estimation, by the integration of current method, with charging efficiency fixed at 0.97 [1], and those from the proposed KF scheme are given, respectively, in Figs. 13 and 14. Having been subjected to a RHOLAB driving cycle, at $\mathrm{t}=1400 \mathrm{~s}$, the tests are terminated and the remnant charge in the cell is measured using a $1.53 \mathrm{~A}$ discharge, to a terminal voltage of $1.7 \mathrm{~V}$ and noting the remaining Ampere hours (Fig. 15). This corresponds 


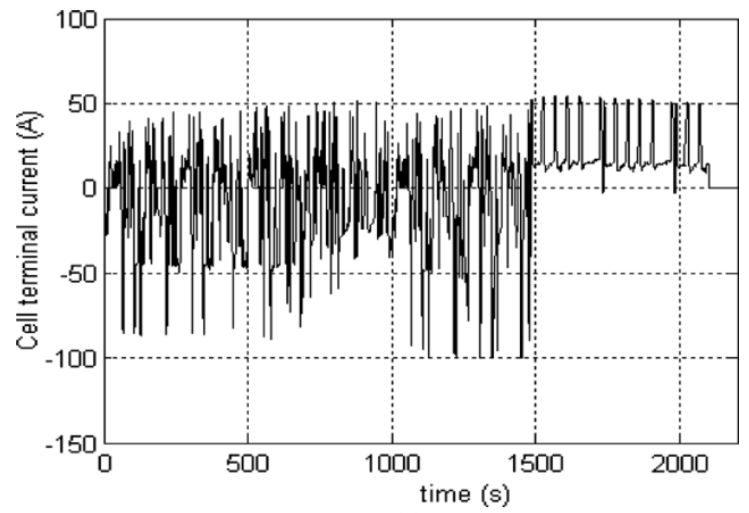

(a)

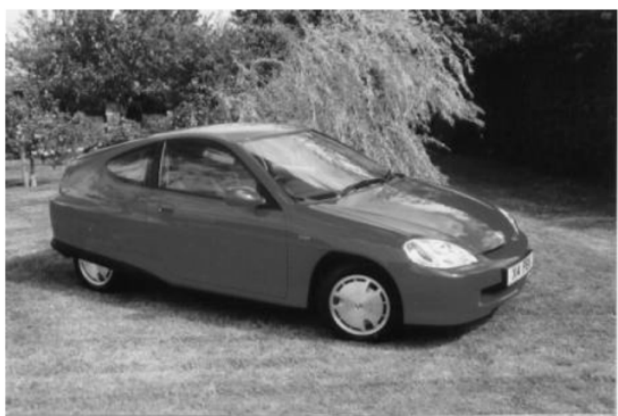

(b)

Fig. 11. (a) Typical RHOLAB [1] driving cycle cell current. (b) RHOLAB Honda Insight HEV employed to gather test data.
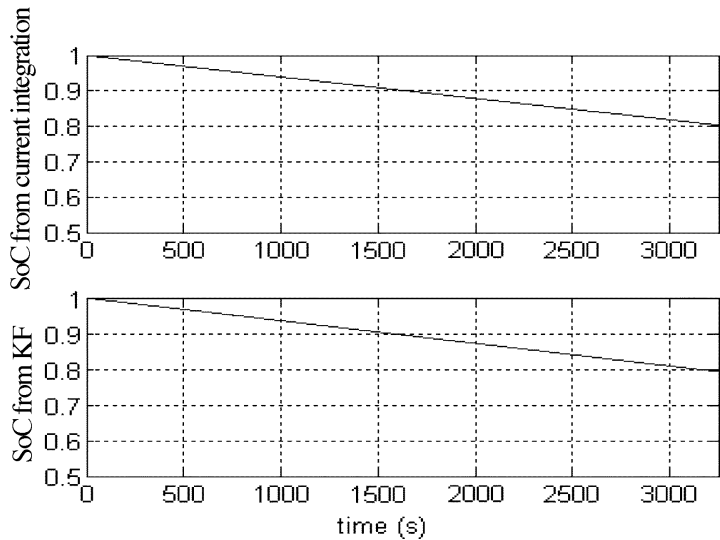

Fig. 12. Discharging a cell from $\mathrm{SoC}$ of $1-0.8$.

to a final SoC of the cell of 0.167 . From Fig. 14, it can be seen that the performance of the KF is excellent and, although both SoC estimation techniques follow the correct profile, the integration-based method demonstrates significant drift over time, with an error of $\approx 15 \%$ ensuing, whereas the KF consistently provides estimates within $\approx 2 \%$ of the measured values.

\section{IMPORTANCE OF THE SoH OF A CELL}

SoH is the ability of a cell to store energy, source and sink high currents, and retain charge over extended periods, relative to its initial or nominal capabilities. The available charge stored within a fully charged cell is expected to fall with cell usage, as

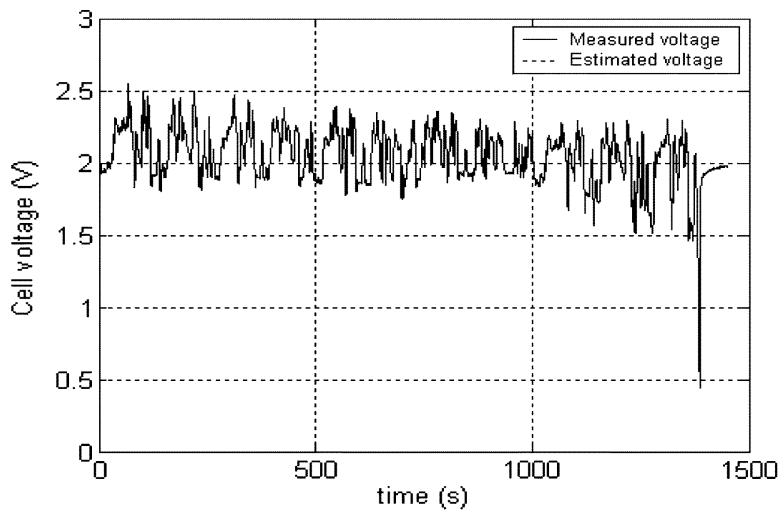

(a)

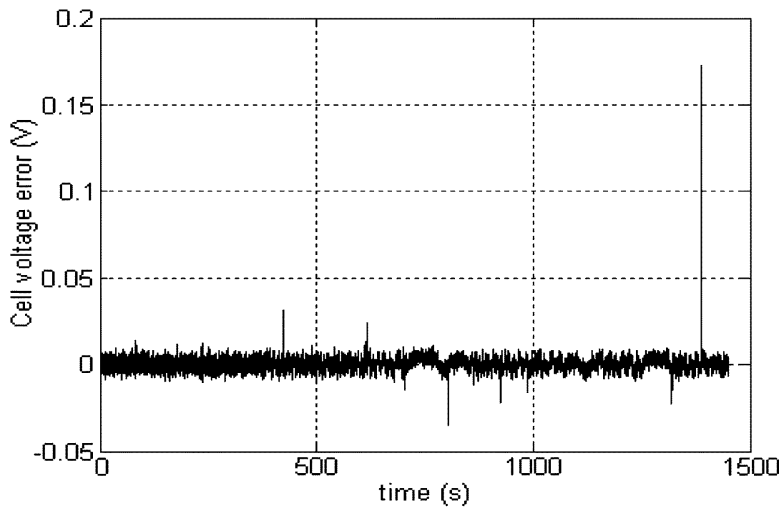

(b)

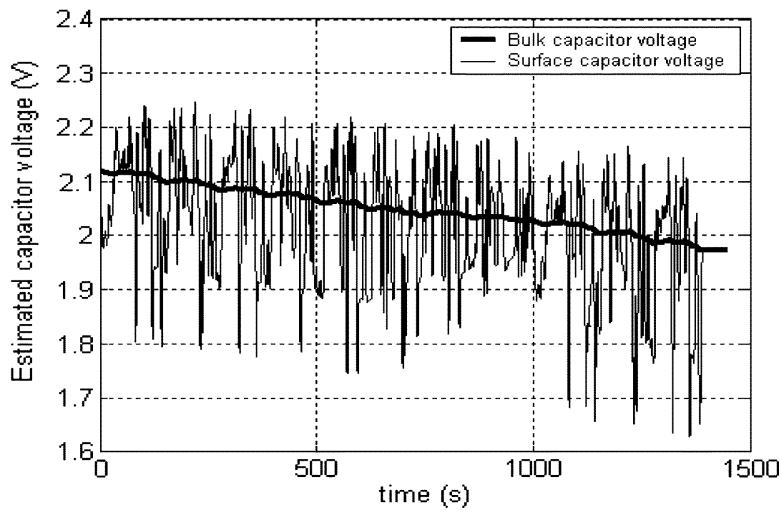

(c)

Fig. 13. Implementation of $\mathrm{KF}$ on cells subjected to RHOLAB cycle. (a) Measured and estimated cell voltage. (b) Cell voltage error. (c) Estimated bulk and surface capacitor voltage.

active material on the cell plates gradually degrades by mechanisms such as loss of plate active surface area due to repeated dissolution and recrystallization, loss of electrical contact between metallic grids and active materials, and growth of large inactive crystals of lead sulphate. Such capacity-loss mechanisms generally occur slowly in VRLA batteries that are cycled at low rates over their full SoC range. However, when operated as a peak power buffer, in a HEV system, the cells are operated at a partial state-of-charge (PSoC), i.e., the cell is never cycled over its full SoC range and is subjected to both high charge and discharge currents. Studies have shown that this PSoC operation can lead to truncated service life in VRLA cells due to the buildup of sulphate within the plate structures, as a result of inefficient recharge of plate material [14], [15]. Such capacity 


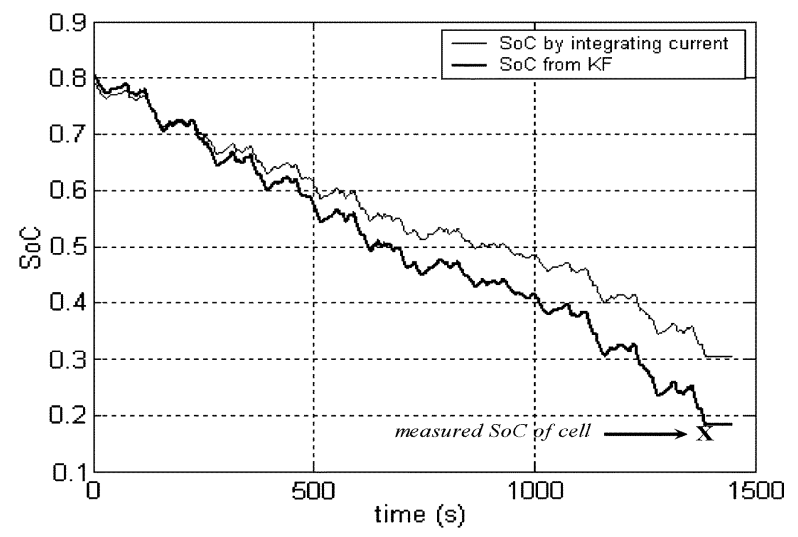

Fig. 14. Comparison of determination of SoC by conventional means by integration of current and from estimated bulk capacitor voltage.

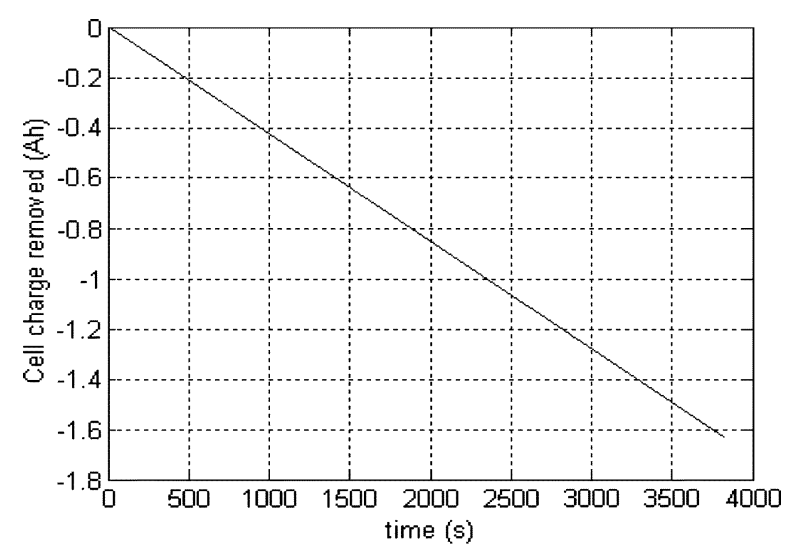

Fig. 15. Cell discharge characteristic to $0 \%$ SoC.

loss can be deemed a loss of cell SoH. Early detection of SoH degradation would allow a "smart" battery pack to take remedial action, such as the application of conditioning routines to the cell, to remove small sulphate crystals before they form large inactive crystals, thereby restoring the cells capacity. Measuring cell capacity by the standard means of a low current discharge is impractical for HEV applications; online techniques that utilize only cell terminal measurements, made while the HEV is driven, are, therefore, required.

\section{A. EKF-Based Estimation of $\mathrm{SoH}$}

A means of estimating bulk capacitance $C_{\text {bulk }}$ requires adding an extra state $d C_{\text {bulk }} / d t=0$ into the observer structure (10) and assuming the rate of change of $C_{\text {bulk }}$, over a sampling interval, is negligible. Since the derivatives of $V_{C b}$ and $V_{0}$ are coupled by nonlinear elements, an EKF is now required for effective estimation of state variables. It should be noted, however, that the realization results in an increase in order of the resulting Jacobians, covariance, noise, and disturbance matrices, with a consequential increase in computation overhead. The proposed nonlinear battery model is written in the form

$$
\begin{aligned}
\dot{x} & =f(x, u) \\
y & =C(x)
\end{aligned}
$$

where $f(x, u)$ is given by

$$
\begin{aligned}
x= & {\left[V_{C b}, V_{C s}, V_{0}, \alpha\right]^{T} } \\
f(x, u)= & {\left[\begin{array}{c}
-\frac{V_{C b} \alpha}{\left(R_{e}+R_{s}\right)}+\frac{V_{C s} \alpha}{\left(R_{e}+R_{s}\right)}+\frac{I R_{s} \alpha}{\left(R_{e}+R_{s}\right)} \\
\frac{1}{C_{\text {surface }}}\left[\frac{V_{C b}}{\left(R_{e}+R_{s}\right)}-\frac{V_{C s}}{\left(R_{e}+R_{s}\right)}+\frac{I R_{e}}{\left(R_{e}+R_{s}\right)}\right] \\
V_{C b} \cdot f 1+V_{0} \cdot f 2+I \cdot f 3
\end{array}\right], } \\
f 1= & -\frac{R_{s} \alpha}{\left(R_{e}+R_{s}\right)^{2}}+\frac{R_{e}}{C_{\text {surface }}\left(R_{e}+R_{s}\right)^{2}} \\
& -\frac{R_{s}^{2} \alpha}{R_{e}\left(R_{e}+R_{s}\right)^{2}}+\frac{R_{s}}{C_{\text {surface }}\left(R_{e}+R_{s}\right)^{2}} \\
f 2= & \frac{R_{s} \alpha}{R_{e}\left(R_{e}+R_{s}\right)}-\frac{1}{C_{\text {surface }}\left(R_{e}+R_{s}\right)} \\
f 3= & \frac{R_{e}^{2}}{C_{\text {surface }}\left(R_{e}+R_{s}\right)^{2}}-\frac{R_{s} R_{t} \alpha}{R_{e}\left(R_{e}+R_{s}\right)} \\
& +\frac{R_{t}}{C_{\text {surface }}\left(R_{e}+R_{s}\right)}+\frac{R_{e} R_{s}}{C_{\text {surface }}\left(R_{e}+R_{s}\right)^{2}}
\end{aligned}
$$

and

$$
\begin{aligned}
C(x) & =V_{0} \\
\alpha & =\frac{1}{C_{\text {bulk }}} .
\end{aligned}
$$

The EKF requires a small-signal model of the system, at each sample step, by linearizing (23) about the current operating point $x_{0}, u_{0}$. From a Taylor series expansion, (ignoring the presence of noise)

$$
\delta \dot{x}=\mathbf{F}(x) \delta x+\mathbf{B} \delta u, \quad \delta y=\mathbf{C} \delta x
$$

where [see (25) at the bottom of the next page].

The resulting small signal model, about the operating point $x_{0}, u_{0}$, is given by

$$
\delta \dot{x}=\mathbf{A}_{k} \delta x+\mathbf{B}_{k} \delta u, \quad \delta y=\mathbf{C} \delta x
$$

(where $\mathbf{A}_{k}=\left.\mathbf{F}(x)\right|_{x_{k}, u_{k}}$ ) that can be discretized, to give

$$
x_{k+1}=\mathbf{A}_{\mathbf{d}} x_{k}+\mathbf{B}_{\mathbf{d}} u_{k} \quad y_{k+1}=\mathbf{C}_{\mathbf{d}} x_{k+1}
$$

and used in the KF algorithm described previously in Fig. 7.

\section{B. Online Implementation of SoH Monitoring}

The SoH of known cells has previously been evaluated [14] by performing continuous power cycling tests [using the RHOLAB profile shown in Fig. 11(a)], on two separate battery packs, each consisting of 18 cells. Results of the tests have demonstrated similar pack lifetimes in each case, over 77 and 74 power cycles, respectively. During the tests, the cells of both packs suffered a measurable mean loss in cell capacity of $\approx 0.01 \mathrm{Ah}$, per power cycle [14]. While performing the tests, the EKF is employed and the variation of $C_{\text {bulk }}$ is estimated. The results, shown in Fig. 16(a), demonstrate the ability of the 
state observer scheme to estimate $C_{\text {bulk }}$, over time, ultimately indicating a reduction of $\approx 10 \%$ during the tests, corresponding to an average loss of cell capacity of $0.8 \mathrm{Ah}$ for a nominal $8 \mathrm{Ah}$ cell. This, therefore, compares well to the measured loss of capacity of $\approx 0.77$ Ah from the packs under test.

A characteristic of the results shown in Fig. 16(a) is the initial rise in the estimated cell capacity at the start of cell cycling. Various reasons contribute to this feature. First, it is recognized that it is difficult to accurately predict initial conditions for the state estimates. In reality, only a mean value of initial bulk capacitance can realistically be employed; hence, the results include an initial period of dynamic convergence to the "true" values. Moreover, from Fig. 16(b), which shows the voltage profile, a corresponding rise in voltage is displayed over the first few cycles, as a consequence of a rise in the internal cell temperature, corresponding to internal Joule and chemical heating within the cell. After $\approx 10$ cycles thermal equilibrium is achieved and the voltage profile displays a near constant envelope. A further contributory factor may be insufficient preconditioning of the cell prior to testing, leading to an initial gain in cell capacity during the first few cycles as active plate materials are cycled through charge/discharge, leading to a fine highly reactive plate crystal structure of a large surface area.

\section{CONCLUSION}

This paper has presented an alternative approach to estimating the $\mathrm{SoC}$ of a cell pack by the application of a KF. It is shown that, when using a generic model (recently applied to lithium-ion cells) to describe the dynamic behavior of lead-acid cells, large state errors can develop over time. However, rather than increasing the complexity of the cell model to closely

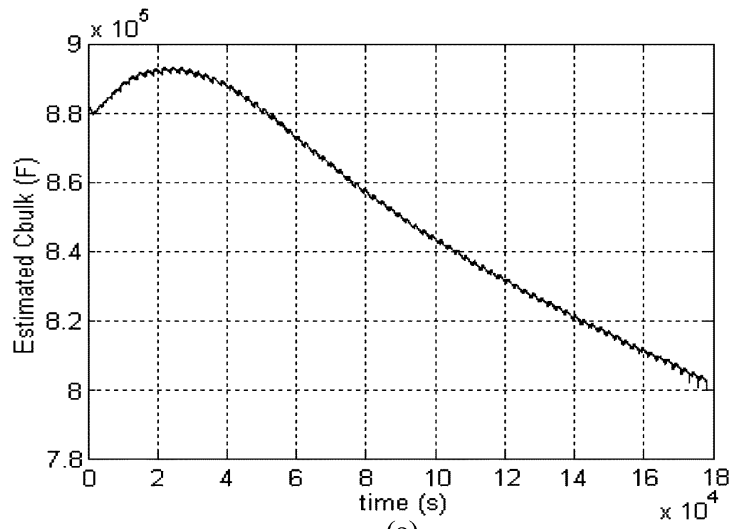

(a)

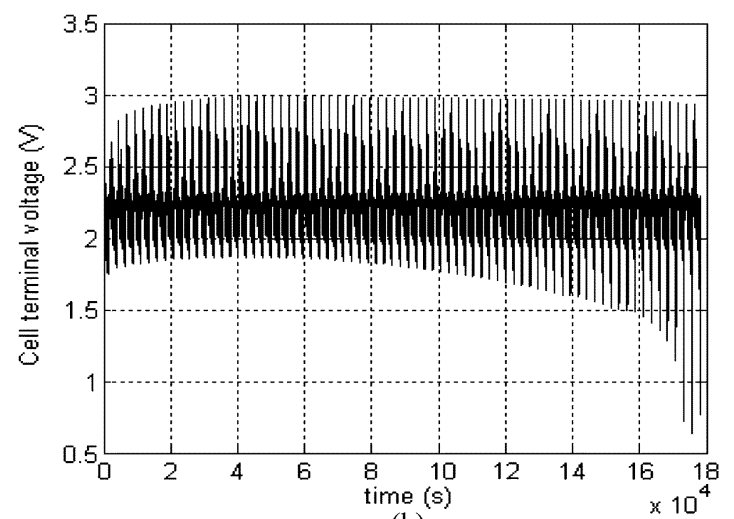

(b)

Fig. 16. EKF employed to predict SoH of the cell pack. (a) Estimated bulk capacitance $C_{\mathrm{bulk}}$. (b) Cell terminal voltage.

match the real system, the application of a KF, with its inherent predictor-corrector mechanism, is shown to accommodate such inadequacies. In particular, a comparison of $\mathrm{SoC}$ estimates

$$
\begin{aligned}
& \delta x=x-x_{0} \quad \delta u=u-u_{0} \\
& \mathbf{F}(x)=\left.\frac{\partial f}{\partial x}\right|_{x(t), u(t)}=\left[\begin{array}{cccc}
-\frac{\alpha}{\left(R_{e}+R_{s}\right)} & \frac{\alpha}{\left(R_{e}+R_{s}\right)} & 0 & F(1,4) \\
\frac{1}{C_{\text {surface }}\left(R_{e}+R_{s}\right)} & -\frac{1}{C_{\text {surface }}\left(R_{e}+R_{s}\right)} & 0 & 0 \\
F(3,1) & 0 & \frac{R_{s} \alpha}{R_{e}\left(R_{e}+R_{s}\right)}-\frac{1}{C_{\text {surface }}\left(R_{e}+R_{s}\right)} & F(3,4) \\
0 & 0 & 0 & 0
\end{array}\right] \\
& F(1,4)=-\frac{V_{C b}}{\left(R_{e}+R_{s}\right)}+\frac{V_{C s}}{\left(R_{e}+R_{s}\right)}+\frac{I R_{s}}{\left(R_{e}+R_{s}\right)} \\
& F(3,1)=-\frac{R_{s} \alpha}{\left(R_{e}+R_{s}\right)^{2}}+\frac{R_{e}}{C_{\text {surface }}\left(R_{e}+R_{s}\right)^{2}}-\frac{R_{s}^{2} \alpha}{R_{e}\left(R_{e}+R_{s}\right)^{2}}+\frac{R_{s}}{C_{\text {surface }}\left(R_{e}+R_{s}\right)^{2}} \\
& F(3,4)=-\frac{V_{C b} R_{s}}{\left(R_{e}+R_{s}\right)^{2}}-\frac{V_{C b} R_{s}^{2}}{R_{e}\left(R_{e}+R_{s}\right)}+\frac{V_{0} R_{s}}{R_{e}\left(R_{e}+R_{s}\right)}-\frac{I R_{s} R_{t}}{R_{e}\left(R_{e}+R_{s}\right)} \\
& \mathbf{B}=\left.\frac{\partial f}{\partial u}\right|_{x(t), u(t)}=\left[\begin{array}{llll}
\frac{R_{s} \alpha}{\left(R_{e}+R_{s}\right)} & \frac{R_{e}}{C_{\text {surface }}\left(R_{e}+R_{s}\right)} & f_{3} & 0
\end{array}\right]^{T} \\
& \mathbf{C}=\left.\frac{\partial C}{\partial x}\right|_{x(t), u(t)}=\left[\begin{array}{llll}
0 & 0 & 1 & 0
\end{array}\right]
\end{aligned}
$$




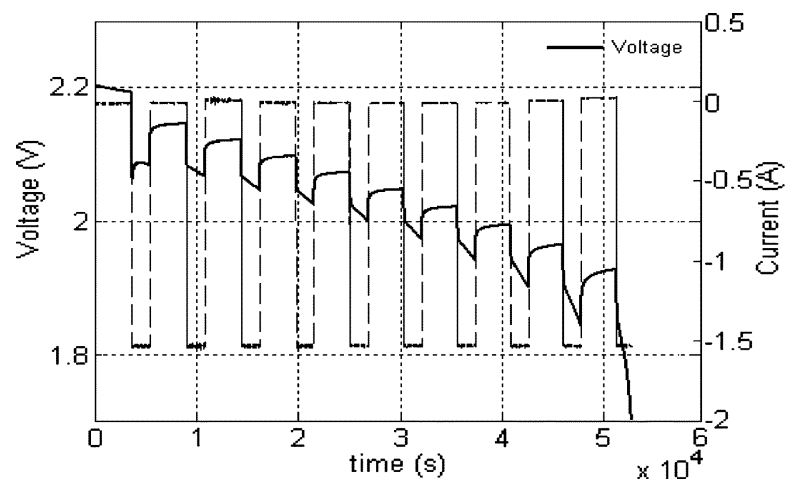

Fig. 17. Cell terminal voltage when discharge current pulses of $1.53 \mathrm{~A}$ are applied.

using the presented KF technique and the more conventional integration of current method is undertaken using "road data" collected from a Honda Insight HEV driven on a test track. The presented results show a significant improvement in SoC estimation from the proposed KF methodology, when compared to more traditional integration of charge methods.

Furthermore, extensions for $\mathrm{SoH}$ monitoring, by employing an EKF, have also been presented-using only measurements of cell terminal quantities as input. Such data is extremely important for the ultimate prediction of SoF, which describes the ability of a cell to perform adequately under HEV demands and is related to both $\mathrm{SoC}$ and $\mathrm{SoH}$ information. SoF will give a prediction of available capacity, and discharge and recharge capability, thereby allowing a "smart" battery to forecast the response of the cell to driving demands, leading to optimal utilization of the battery pack with regard to performance and lifetime and, therefore, better overall energy management within the vehicle.

It is notable that, while the presented work has focused on a specific battery model, ultimately, due to presented benefits, it is expected that similar state-estimation schemes will be adopted for other model structures and cell chemistries.

\section{APPENDIX}

\section{A. Calculation of Initial Parameters}

Initial parameters required for the battery model are determined from experimental data, where OCV tests are performed upon successive discharge of battery by injection of current pulses.

1) Capacitor $C_{\text {bulk: }}$ : The capacitance is determined by analyzing the amount of stored energy. Fig. 17 shows the OCV when discharge current pulses of $1.53 \mathrm{~A}$ are applied for $1800 \mathrm{~s}$ at 3600-s intervals.

The energy stored in $C_{\text {bulk }}$ is determined from the OCV at $0 \%$ SOC and $100 \%$ SOC, using the following expression:

$$
\begin{aligned}
C_{\text {bulk_energy }} & =\frac{1}{2} C_{\mathrm{bulk}} V^{2} \\
& =\frac{1}{2} C_{\mathrm{bulk}}\left(V_{100 \% \mathrm{SOC}}^{2}-V_{0 \% \mathrm{SOC}}^{2}\right)
\end{aligned}
$$

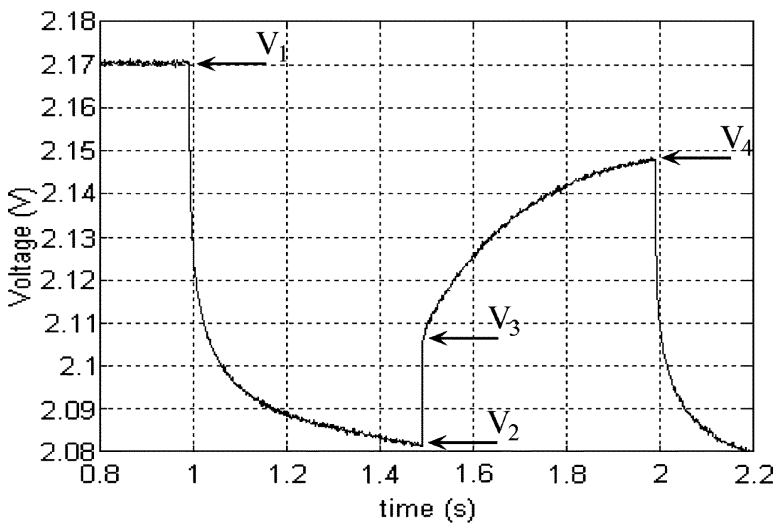

Fig. 18. Cell terminal voltage when a discharge current of $10 \mathrm{~A}$ pulse is applied at 500-ms intervals.

$C_{\text {bulk_energy }}$ is equivalent to the rated Amp-sec capacity of the battery, giving:

$$
C_{\text {bulk_initial }}=\frac{\text { Rated }(\mathrm{AmpSec}) \times V_{100 \% \mathrm{SOC}}}{\frac{1}{2}\left(V_{100 \% \mathrm{SOC}}^{2}-V_{0 \% \mathrm{SOC}}^{2}\right)} .
$$

2) Capacitor $C_{\text {surface }}$ : An initial value of $C_{\text {surface }}$ relies on results of high-frequency excitation of the cell to determine the time constant given by the surface capacitor and its associated resistance. As before, OCV tests are performed. Discharge pulses of $10 \mathrm{~A}$ are applied at 500-ms intervals, thereby isolating the results from the effects of $C_{\text {bulk }}$.

From Fig. 18, it is seen that

$$
\begin{aligned}
V_{1} & =2.171 \\
V_{2} & =2.082 \\
V_{3} & =2.106 \\
V_{4} & =2.148 \\
\Delta t & =0.5 .
\end{aligned}
$$

The time constant is approximated using the following relationship:

$$
V_{\text {no_load }}(t)=V_{1}=V_{3}+\left(V_{4}-V_{3}\right)\left(1-e^{-\frac{t}{\tau}}\right)
$$

and solving for $\tau$ gives

$\tau=-\Delta t \ln \left(1-\frac{V_{4}-V_{3}}{V_{1}-V_{3}}\right)=-0.5 \ln \left(1-\frac{0.042}{0.065}\right)=0.5914$

The time constant is described by

$$
\tau=\left(R_{e}+R_{s}\right) C_{\text {surface }}
$$

Hence, the initial estimate of surface capacitor, is determined as

$$
C_{\text {surface_initial }}=\frac{\tau}{R_{e}+R_{s}} .
$$


TABLE I

INITIAL PARAMETERS FOR THE CELl MODEL

\begin{tabular}{l|l}
\hline$C_{\text {bulk }}$ & $88372.83 \mathrm{~F}$ \\
$C_{\text {surface }}$ & $82.11 \mathrm{~F}$ \\
$R_{e}$ & $0.00375 \Omega$ \\
$R_{s}$ & $0.00375 \Omega$ \\
$R_{t}$ & $0.002745 \Omega$ \\
\hline
\end{tabular}

3) Battery Resistance: The internal resistance of the battery is measured as $4.6 \mathrm{~m} \Omega$. It is assumed that $R_{e}$ and $R_{s}$ are equivalent and account for $75 \%$ of total resistance. Hence, $R_{t}$ is

$$
0.0046=R_{t}+\left[\frac{1}{R_{e}}+\frac{1}{R_{s}}\right] .
$$

A summary of initial values is given in Table I.

\section{REFERENCES}

[1] M. J. Kellaway, P. Jennings, D. Stone, E. Crowe, and A. Cooper, "Early results from a systems approach to improving the performance and lifetime of lead acid batteries," J. Power Sources, vol. 116, pp. 110-117, 2003.

[2] S. Piller, M. Perrin, and A. Jossen, "Methods for state-of-charge determination and their applications," J. Power Sources, vol. 96, pp. 113-120, 2001.

[3] O. Caumont, Ph. Le Moigne, P. Lenain, and C. Rombaut, "An optimized state of charge algorithm for lead-acid batteries in electric vehicles," in Electric Vehicle Symp. , vol. EVS-15, Brussels, Belgium, Sep-Oct. 30-3, 1998. Proceedings on CD-ROM.

[4] H. Bode, Lead Acid Batteries. New York: Wiley, 1977.

[5] F. Huet, "A review of impedance measurements for determination of the state-of-charge or state of health of secondary batteries," J. Power Sources, vol. 70, pp. 59-69, 1998.

[6] S. Rodrigues, N. Munichandraiah, and A. K. Shukla, "A review of state-of-charge indication of batteries by means of a.c. impedance measurements," J. Power Sources, vol. 87, pp. 12-20, 2000.

[7] C. C. Chan, E. W. C. Lo, and S. Weixiang, "The available capacity computation model based on artificial neural network for lead acid batteries in electric vehicles," J. Power Sources, vol. 87, pp. 201-204, 2000.

[8] P. Singh, C. Fennie, D. E. Reisner, and A. Salkind, "A fuzzy logic approach to state-of-charge determination in high performance batteries with applications to electric vehicles," in Electric Vehicle Symp., vol. EVS-15, Brussels, Belgium, Sep.-Oct. 30-3, 1998. Proceedings on CD-ROM.

[9] G. O. Patillon and J. N. d'Alché-Buc, "Neural network adaptive modeling of battery discharge behavior," in Artificial Neural Networks ICANN'97 7th Int. Conf., vol. 1327, Lecture Notes in Computer Science. Berlin, Germany, 1997, pp. 1095-1100.

[10] S. R. Bhatikar, R. L. Mahajan, K. Wipke, and V. Johnson. (1999, Aug.) Neural Network based energy storage system modeling for hybrid electric vehicles. Nat. Renewable Energy Lab., Golden, CO. [Online] www.ctts.nrel.gov/analysis/reading_room.

[11] R. E. Kalman, "A new approach to linear filtering and prediction problems," Trans. ASME, ser. D, pp. 35-45, 1982.

[12] R. Bucy, R. Kalman, and I. Selin, "Comment on the Kalman filter and nonlinear estimates of multivariate normal processes," IEEE Trans. Autom. Control, vol. AC-10, no. 1, pp. 118-119, Jan. 1965.

[13] V. H. Johnson, A. A. Pesaran, and T. Sack, "Temperature-dependent battery models for high-power lithium-ion batteries," presented at the Proc. EVS 17, Montreal, PQ, Canada, 2000.

[14] P. Bentley and D. A. Stone, "Lifetime extension of Valve regulated lead acid (VRLA) batteries under hybrid vehicle duty," in Proc. 2nd Int. Power Electronics Machines and Drives Conf. (PEMD'04), vol. 1, Edinburgh, U.K., 2004, pp. 49-54.
[15] D. A. Hollenkamp, D. A. Baldsing, and D. A. Lim et al., Overcoming negative-plate capacity loss in VRLA batteries cycled under partial state-of-charge duty, in Advanced Lead Acid Battery Consortium (ALABC) Invest. Rep. ET/IR398R, Research Triangle Park, NC, 2001.

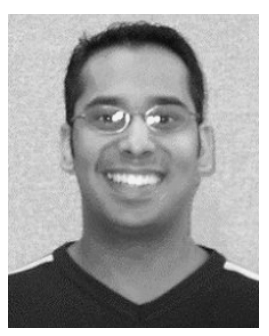

B. S. Bhangu (M'03) received the B.Eng. degree in electrical and electronic engineering from Nottingham University, Nottingham, U.K., in 1998 and the MSc. degree in control systems and the $\mathrm{Ph} . \mathrm{D}$. degree for his work on sensorless control of brushless-AC machines for power assisted steering systems from the University of Sheffield, Sheffield, U.K., in 1999 and 2004, respectively.

He currently holds a postdoctoral research post at the University of Sheffield. His research interests include sensorless control of brushless machines for automotive and aerospace applications and modeling of hybrid-electric vehicles and battery-management techniques.

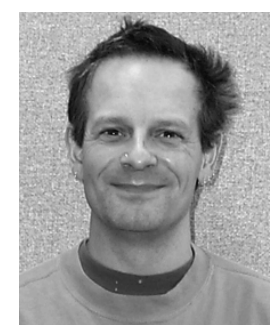

P. Bentley received the BSc. degree in engineering physics from Sheffield Hallam University, Sheffield, U.K., and the Ph.D. for the dynamic characterization and modeling of battery technologies for all/more electric vehicles from the University of Sheffield, Sheffield, U.K., in 1998 and 2004, respectively.

He currently is a Research Associate with the University of Sheffield. His research interests include energy storage components for hybrid and electric vehicle drive-trains.

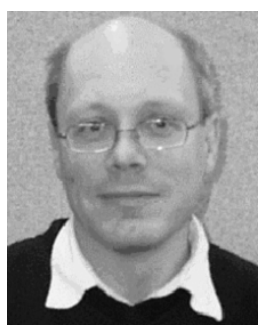

D. A. Stone received the B.Eng. degree in electronic engineering from the University of Sheffield, Sheffield, U.K., and the Ph.D. degree from Liverpool University, Liverpool, U.K., in 1984 and 1989, respectively.

$\mathrm{He}$ is with the University of Sheffield as a Member of Academic Staff, specializing in power electronics and machine drive systems. His current research interests include hybrid-electric vehicles, battery charging, EMC, and novel lamp ballasts for low-pressure fluorescent lamps.

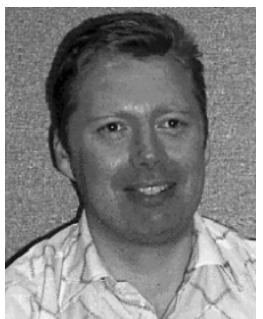

C. M. Bingham (M'00) received the B.Eng. degree in electronic systems and control engineering from Sheffield City Polytechnic, Sheffield, U.K., in 1989, the M.Sc. (Eng.) degree in control systems engineering from the University of Sheffield, Sheffield, U.K., in 1990, and Ph.D. degree from Cranfield University, U.K., in 1994, for research on control systems to accommodate nonlinear dynamic effects in aerospace flight-surface actuators.

He was a Postdoctoral Researcher with Cranfield University until taking a research position at the University of Sheffield. He was appointed Lecturer in the Department of Electronic and Electrical Engineering, University of Sheffield, in 1998 and Senior Lecturer in 2003. His current research interests include traction control/antilock braking systems for electric vehicles, electromechanical actuation of flight control surfaces, control of active magnetic bearings for high-speed machines, sensorless control of brushless machines, and the high-speed modeling, analysis, and design of resonant power converters. 